\title{
Model Estimation for LongitudinalBone Growth Based on Age in Male and Female Commercial Broiler Chickens
}

\author{
Saijai Kongpechr ${ }^{1}$, Damnern Sohsuebngarm ${ }^{1}$ and Peerapol Sukon ${ }^{1,2^{*}}$ \\ ${ }^{\text {I}}$ Faculty of Veterinary Medicine, Khon Kaen University, Thailand \\ ${ }^{2}$ Research Group for Animal Health Technology, Khon Kaen University, Thailand \\ *Corresponding author’s E-mail: sukonp@kku.ac.th; ORCID: 0000-0002-0899-2572
}

\begin{abstract}
Longitudinal bone growth is essential to support rapid body growth in commercial broiler chickens. The present study aimed to determine which simple mathematic model is best suitable for explaining the absolute and the relative bone growth in length (expressed as a ratio of bone length to body weight) as a function of age in male and female commercial broiler chickens over the first 35 days of age. A total of 1,800 broiler chickens (900 males and 900 females) of Cobb 500, Ross 308, and Arbor Acres raised in standard commercial broiler houses were randomly selected for this study. Body weight and the lengths of backbones, third toe, shank bone, and keel bone were individually measured in all chickens at 1, 7, 14, 21, 28, and 35 days of age. Regression analysis (with 4 simple mathematical models including linear, logarithmic, inverse, and exponential) was used to find a suitable model for estimating the absolute and the relative bone growth in length. In addition, an adjusted $\mathrm{R}^{2}$ was used to assess the model fitting. The results indicated that the absolute bone growth in length linearly increased with age. The adjusted $\mathrm{R}^{2}$ values for the linear model were $0.973,0.937,0.950$, and 0.974 for the lengths of the backbones, third toe, shank bone, and keel bone, respectively. However, the relative bone growth in length logarithmically decreased with age. The adjusted $\mathrm{R}^{2}$ values of the logarithmic model were $0.971,0.952,0.957$, and 0.905 for the relative length of the backbones, third toe, shank bone, and keel bone, respectively. The present investigation suggests thata linear model is a suitable model for estimating the absolute bone growth in length, but a logarithmic model is a proper model for estimating the relative bone growth in length of commercial broiler chickens.
\end{abstract}

Received: 20Jul. 2019

Accepted: 19Aug. 2019

Key words:Age, Bone growth, Broiler chickens, Mathematical model, Regression

\section{INTRODUCTION}

The meat of broiler chickens is a popular and cheap protein source for humans worldwide. To serve a huge demand with affordable cost for consumers, fast-growing strains of commercial broiler chickens are necessary. At present, commercial broiler chickens can reach a market size of $2.2 \mathrm{~kg}$ within 35 days of age (Tallentire et al., 2018). The percentages of breast plus leg muscles of these chickens accounts for more than $40 \%$ of whole eviscerated carcasses (Kokoszyński and Bernacki, 2008; Sarsenbek et al., 2013). However, due to a very rapid growth rate, fastgrowing commercial broiler chickens face several problems or disorders, especially in bone and leg (Cook, 2000; Knowles et al., 2008; Granquist et al., 2019). The skeletonis an important structure that supports the whole body; therefore, bone growth is a key physiological process to ensure a proper supporting system for the whole body of animals. Bone growth has many aspects, such as circumferential growth, weight growth, volume growth, bone mineralization, chemical composition, and structural organization (Rose et al., 1996; Kerschnitzki et al., 2016; Pratt and Cooper, 2018; Sanchez-Rodriguez et al., 2019). Bone growth in length (or longitudinal bone growth) is an important factor that supports the rapid expansion of the body of broiler chickens. Several studies have indicated that absolute rate of longitudinal bone growth is positively associated with the age or weight of broiler chickens (Applegate and Lilburn, 2002; Biesiada-Drzaga et al., 2012; Han et al., 2015; Mabelebele et al., 2017). However, one study indicated that relative bone growth in length, expressed as a ratio of bone length to body weight, was negatively associated with body weight gain in broiler chickens (Shim et al., 2012). This ratio is a useful variable to assess the rate of bone length compared to the rate of body weight gain as a function of age. To better understand the bone growth in length as a function of age 
in broiler chickens, the objective of this study was to determine which simple mathematical model is suitable for explaining the absolute and the relative bone growth in length in male and female commercial broiler chickens over the first 35 days of the rearing period.

\section{MATERIALS AND METHODS}

\section{Ethical approval}

The study was approved by the Institutional Animal Care and Use Committee of Khon Kaen University, Khon Kaen, Thailand (ACUC KKU license No. 27/2559).

\section{Animals and housing}

The present study was conducted in six broiler houses (three each) from two commercial broiler farms located in Buriram Province, Northeastern Thailand on June 2018 (Latitude: 14 36' 21.31" N, Longitude: 103 ${ }^{\circ}$ $\left.07^{\prime} 14.92 " \mathrm{E}\right)$. The year-round outside temperature was approximately $27{ }^{\circ} \mathrm{C}$, and the relative humidity was approximately $75 \%$. Both farms used a tunnel ventilated house with dimensions of $14 \times 2.8 \times 120 \mathrm{~m}$ (width $\mathrm{x}$ height $x$ length), resulting in a $1,680 \mathrm{~m}^{2}$ rearing area. Each house was equipped with a cooling pad on both lateral sides near the front end and 10 large exhaust fans at the rear end. Each house was equipped with four rows of automatic feeding pans, totaling 644 pans, and five rows of the drinkers, totaling 2,366 heads. The stock density was 11-12.5 heads per square meter, resulting in 18,000 to 21,000 birds per house. Each house was considered for both sexes but with a single breed. Chickens were reared in floor pens. The floor was made from concrete cement and covered with a $5 \mathrm{~cm}$ thick layer of new rice husk for each growing cycle. Diet, feeding, vaccination, husbandry, and care of the broiler chickens were under standard conditions depending on the age of chickens recommended by the broiler breeder companies. Briefly, feed and water were provided ad libitum throughout the rearing cycle. Starter, grower, and finisher feed were used for chickens at aged 1-21 days, 22-32 days, and 33 days until the end of the rearing period, respectively. All chickens were vaccinated against Newcastle disease and infectious bronchitis according to a routine vaccination program. In addition, the chickens were regularly inspected for health status by a veterinarian. The flocks and the farms had no history of disease outbreaks. The temperature in the poultry house was controlled by using a heater or tunnel ventilation system depending on the age of chickens to provide the optimal conditions for birds according to the guidelines for commercial broilers.

\section{Study design, sampling, and outcome measurements}

This observational study was designed based on three chick characteristics as follows: age with six levels $(1,7,14,21,28$, and 35 days of age), sex with two categories(male and female), and breed with three types (Cobb 500, Ross 308, and Arbor Acres). Therefore, 36 subgroups were included and 50 healthy broiler chickens were randomly selected from the flocks for each subgroup. This resulted in a total sample of 1,800 broiler chickens. All samples were randomly selected from the flocks around the middle of the commercial broiler house (approximately 60 meters from the front end of the house). All measurements were made non-invasively on living animals. For a selected chicken, the body weight was measured with a digital weight scale. Moreover, the length of the backbones, a third toe, a shank bone (a tarsometatarsus), and a keel bone was measured with a Vernier caliper. All variables were measured in living birds using two people (one held the bird gently and another one made the measurement). After birds were measured, they were returned to their flocks. The total length of the backbones (including thoracic, lumbosacral, and caudal vertebrae) was measured from the junction of the last cervical vertebra to the distal end of the last caudal vertebra. The third toe was measured from the proximal end (metatarso-digital joint) to the tip of the claw. The shank bone was measured from the proximal end to the distal end. The keel bone was measured from the proximal end to the distal end. The original measurement scale was in grams for body weight and in millimeters for the bones length.

\section{Statistical analysis}

All data from each variable were verified and checked for normality. The mean and standard deviation from each variable for males and females at six different ages $(1,7,14,21,28$, and 35 days) of broiler chickens were calculated. A mean difference of each variable was compared using an independent sample t-test. The relative bone growth in length was calculated as a ratio of bone length to body weight. To avoid many decimals and for ease of interpretation, this ratio was expressed in $\mathrm{cm} / \mathrm{kg}$. Regression analysis with four mathematical models was used to estimate the absolute and relative bone growth in length as a function of age in broiler chickens. These mathematical models included linear, logarithmic, inverse, and exponential models. The mathematical equation for each model was as follows.

$$
\text { Linear model: } Y=b 0+(b 1 * t) \text {. }
$$


Logarithmic model: $Y=b 0+(b 1 * \log (t))$.

Inverse model: $Y=b 0+(b 1 / t)$.

Exponential model: $Y=b 0 *\left(e^{* *}(b l * t)\right)$.

( $Y$ stands for the dependent variable; $b 0$ for the intercept; $b l$ for the slope; $e$ for an irrational constant (approximately equal to 2.718); and $t$ for the independent variable (age of chickens)). A p-value of $<0.05$ was considered statistically significant. SPSS version 17 (SPSS Inc, Chicago, IL) was used for all statistical analysis.

\section{RESULTS}

The mean and standard deviation of the body weight of male and female broiler chickens at 1, 7, 14, 21, 28, and 35 days of age is shown in table 1 . The difference in mean body weight was significantly higher in males than in females starting from days 7 through 35 . The effect sizes of the mean differences were $4.9 \mathrm{~g}$ at 7 days to $260 \mathrm{~g}$ at 35 days of age.

Comparison of the absolute and the relative bone growth in length between the studied male and female broiler chickens for the backbones, the third toe, the shank bone, and the keel bone are presented in tables 2-5. At 28 and 35 days of age, the absolute length of the backbones was significantly greater in males than in females; however, the relative length was significantly smaller in males compared to females at 7, 14, 21, 28, and 35 days of age (Table 2). The absolute length of the third toe was significantly greater in males than in females at 21,28 , and 35 days of age; however, the relative length was significantly smaller in males than in females at 7, 14, 21, 28 , and 35 days of age (Table 3 ). The absolute length of the shank bone was significantly greater in males than in females at 14, 28, and 35 days of age; however, the relative length was significantly smaller in males than in females at 7, 21, 28, and 35 days of age (Table 4). The absolute length of the keel bone was significantly greater in males than in females at 14, 21, 28, and 35 days of age; however, the relative length was significantly smaller in males than in females at 7, 14, 21, 28, and 35 days of age (Table 5).

Regression analysis of linear, logarithmic, inverse, and exponential models for estimating the association between the absolute bone growth in length and the age of the broiler chickens are shown in table 6. The regression coefficient of the absolute bone length as a function of age was significant for all models and for all the studied bones $(\mathrm{p}<0.001)$ (Table 6). However, the adjusted $\mathrm{R}^{2}$ was the greatest for the linear model for all bone types (0.973, $0.937,0.950$, and 0.974 for backbones, third toe, the shank bone, and the keel bone; respectively) (Table 6). Visually, a linear model was a better model than a logarithmic model in fitting the data for the absolute bone growth in length in the broiler chickens (Figure 1A-4A). In the linear model, a regression coefficient for age was positively maximal for the keel bone (3.46) and positively minimal for the third toe (1.13) (Table 6).

Regression analysis with four different models (linear, logarithmic, inverse, and exponential models) for estimating the association between the relative bone growth in length and age of broiler chickens are presented in table 7 . The regression coefficient of the relative bone length as a function of age was significant for all the models and for all the bones $(\mathrm{p}<0.001)$ (Table 7). However, the adjusted $\mathrm{R}^{2}$ was the greatest for the logarithmic model for most bone types $(0.971$ for backbones, 0.952 for the third toe, 0.957 for the shank bone, and 0.905 for the keel bone) (Table 7). Visually, the logarithmic model was a better model than the linear model in fitting the data for the relative bone growth in length in the broiler chickens (Figure 1B-4B). In the logarithmic model, a regression coefficient for age was negatively maximal for the keel bone (-31.28) and negatively minimal for the third toe $(-13.44)$ (Table 7).

Table 1. Body weight of broiler chickens at different ages

\begin{tabular}{|c|c|c|c|c|}
\hline Age of chickens (day) & $\begin{array}{c}\text { Male } \\
\text { Mean } \pm \text { SD }\end{array}$ & $\begin{array}{c}\text { Female } \\
\text { Mean } \pm \text { SD }\end{array}$ & MD $(95 \% \mathrm{CI})$ & p-value \\
\hline 1 & $43.6 \pm 2.5$ & $44.0 \pm 2.7$ & $-0.4(-1.0,0.2)$ & 0.181 \\
\hline 14 & $479.5 \pm 15.7$ & $462.0 \pm 12.8$ & $17.5(14.3,20.8)$ & $<0.001$ \\
\hline 21 & $959.6 \pm 15.1$ & $902.2 \pm 16.1$ & $57.3(53.8,60.9)$ & $<0.001$ \\
\hline
\end{tabular}

CI: confidence interval, MD: mean difference, SD: standard deviation 
Table 2. The absolute length and relative length (expressed as a ratio of bone length to body weight) of backbones in male and female broiler chickens at different ages

\begin{tabular}{lcccc|cccc}
\hline \multirow{2}{*}{$\begin{array}{l}\text { Age } \\
\text { (days) }\end{array}$} & \multicolumn{3}{c}{ Absolute length of backbones $(\mathbf{m m})$} & \multicolumn{3}{c}{ Relative length of backbones $(\mathbf{c m} / \mathbf{k g})$} \\
\cline { 2 - 9 } & $\begin{array}{c}\text { Male } \\
\text { Mean } \pm \text { SD }\end{array}$ & $\begin{array}{c}\text { Female } \\
\text { Mean } \pm \text { SD }\end{array}$ & MD $(\mathbf{9 5 \%}$ CI) & p-value & $\begin{array}{c}\text { Male } \\
\text { Mean } \pm \text { SD }\end{array}$ & $\begin{array}{c}\text { Female } \\
\text { Mean } \pm \text { SD }\end{array}$ & MD (95\% CI) & p-value \\
\hline 1 & $50.8 \pm 2.4$ & $50.0 \pm 2.0$ & $0.8(0.3,1.3)$ & 0.001 & $116.9 \pm 7.8$ & $114.0 \pm 7.9$ & $2.9(1.1,4.6)$ & 0.002 \\
7 & $79.6 \pm 4.8$ & $80.6 \pm 3.6$ & $-1.0(-2.0,0.0)$ & 0.042 & $44.2 \pm 3.6$ & $46.2 \pm 4.7$ & $-2.0(-2.9,-1.1)$ & $<0.001$ \\
14 & $100.0 \pm 9.1$ & $103.9 \pm 5.4$ & $-3.8(-5.5,-2.1)$ & $<0.001$ & $20.9 \pm 1.9$ & $22.5 \pm 1.3$ & $-1.6(-2.0,-1.3)$ & $<0.001$ \\
21 & $118.6 \pm 3.8$ & $119.9 \pm 5.7$ & $-1.3(-2.4,-0.2)$ & 0.021 & $12.4 \pm 0.4$ & $13.3 \pm 0.6$ & $-0.9(-1.0,-0.8)$ & $<0.001$ \\
28 & $146.4 \pm 5.8$ & $143.2 \pm 4.2$ & $3.2(2.0,4.3)$ & $<0.001$ & $9.3 \pm 0.4$ & $10.0 \pm 0.4$ & $-0.7(-0.8,-0.6)$ & $<0.001$ \\
35 & $169.6 \pm 7.5$ & $165.2 \pm 5.8$ & $4.4(2.9,6.0)$ & $<0.001$ & $7.4 \pm 0.4$ & $8.2 \pm 0.3$ & $-0.7(-0.8,-0.7)$ & $<0.001$ \\
\hline
\end{tabular}

CI: confidence interval, MD: mean difference, SD: standard deviation

Table 3. The absolute length and the relative length (expressed as a ratio of bone length to body weight) of the third toe in male and female broiler chickens at different ages

\begin{tabular}{lcccc|cccc}
\hline \multirow{2}{*}{$\begin{array}{l}\text { Age } \\
\text { (days) }\end{array}$} & \multicolumn{3}{c}{ Absolute length of the third toe $(\mathbf{m m})$} & \multicolumn{3}{c}{ Relative length of the third toe $(\mathrm{cm} / \mathbf{k g})$} \\
\cline { 2 - 9 } & $\begin{array}{c}\text { Male } \\
\text { Mean } \pm \text { SD }\end{array}$ & $\begin{array}{c}\text { Female } \\
\text { Mean } \pm \text { SD }\end{array}$ & MD (95\% CI) & p-value & $\begin{array}{c}\text { Male } \\
\text { Mean } \pm \text { SD }\end{array}$ & $\begin{array}{c}\text { Female } \\
\text { Mean } \pm \text { SD }\end{array}$ & MD (95\% CI) & p-value \\
\hline 1 & $21.4 \pm 2.2$ & $21.5 \pm 1.7$ & $-0.1(-0.5,0.4)$ & 0.814 & $49.3 \pm 6.5$ & $49.0 \pm 5.8$ & $0.3(-1.1,1.7)$ & 0.667 \\
7 & $32.4 \pm 1.5$ & $32.6 \pm 1.4$ & $-0.1(-0.5,0.2)$ & 0.444 & $18.0 \pm 1.7$ & $18.7 \pm 2.3$ & $-0.7(-1.1,-0.2)$ & 0.005 \\
14 & $41.5 \pm 3.1$ & $41.1 \pm 2.2$ & $0.4(-0.3,1.0)$ & 0.248 & $8.7 \pm 0.7$ & $8.9 \pm 0.5$ & $-0.3(-0.4,-0.1)$ & 0.001 \\
21 & $46.2 \pm 1.6$ & $45.8 \pm 1.7$ & $0.4(0.0,0.8)$ & 0.033 & $4.8 \pm 0.2$ & $5.1 \pm 0.2$ & $-0.3(-0.3,-0.2)$ & $<0.001$ \\
28 & $56.3 \pm 3.3$ & $54.3 \pm 3.2$ & $2.0(1.2,2.7)$ & $<0.001$ & $3.6 \pm 0.2$ & $3.8 \pm 0.3$ & $-0.2(-0.3,-0.2)$ & $<0.001$ \\
35 & $62.7 \pm 5.0$ & $59.4 \pm 4.1$ & $3.3(2.3,4.3)$ & $<0.001$ & $2.7 \pm 0.2$ & $2.9 \pm 0.2$ & $-0.2(-0.2,-0.1)$ & $<0.001$ \\
\hline
\end{tabular}

CI: confidence interval, MD: mean difference, SD: standard deviation

Table 4. The absolute length and relative length (expressed as a ratio of bone length to body weight) of the shank bone in male and female broiler chickens at different ages

\begin{tabular}{|c|c|c|c|c|c|c|c|c|}
\hline \multirow{2}{*}{$\begin{array}{l}\text { Age } \\
\text { (days) }\end{array}$} & \multicolumn{4}{|c|}{ Absolute length of the shank bone (mm) } & \multicolumn{4}{|c|}{ Relative length of the shank bone $(\mathrm{cm} / \mathrm{kg})$} \\
\hline & $\begin{array}{c}\text { Male } \\
\text { Mean } \pm \text { SD }\end{array}$ & $\begin{array}{c}\text { Female } \\
\text { Mean } \pm \text { SD }\end{array}$ & MD $(95 \%$ CI $)$ & P-value & $\begin{array}{c}\text { Male } \\
\text { Mean } \pm \text { SD }\end{array}$ & $\begin{array}{c}\text { Female } \\
\text { Mean } \pm \text { SD }\end{array}$ & MD $(95 \%$ CI $)$ & P-value \\
\hline 1 & $29.1 \pm 2.0$ & $29.0 \pm 1.4$ & $0.1(-0.3,0.5)$ & 0.576 & $66.8 \pm 5.3$ & $66.0 \pm 4.3$ & $0.9(-0.2,1.9)$ & 0.127 \\
\hline 14 & $54.2 \pm 3.5$ & $52.5 \pm 2.4$ & $1.7(1.0,2.4)$ & $<0.001$ & $11.3 \pm 0.8$ & $11.4 \pm 0.6$ & $-0.1(-0.2,0.1)$ & 0.478 \\
\hline 21 & $63.1 \pm 8.2$ & $61.9 \pm 8.1$ & $1.2(-0.7,3.0)$ & 0.214 & $6.6 \pm 0.8$ & $6.9 \pm 0.9$ & $-0.3(-0.5,-0.1)$ & 0.003 \\
\hline
\end{tabular}

CI: confidence interval, MD: mean difference, SD: standard deviation

Table 5. The absolute length and the relative length (expressed as a ratio of bone length to body weight) of keel bone in male and female broiler chickens at different ages

\begin{tabular}{lcccc|cccc}
\hline \multirow{2}{*}{$\begin{array}{l}\text { Age } \\
(\text { days })\end{array}$} & \multicolumn{3}{c}{ Absolute length of the keel bone $(\mathbf{m m})$} & \multicolumn{3}{c}{ Relative length of the keel bone $(\mathbf{c m} / \mathrm{kg})$} \\
\cline { 2 - 9 } & $\begin{array}{c}\text { Male } \\
\text { Mean } \pm \text { SD }\end{array}$ & $\begin{array}{c}\text { Female } \\
\text { Mean } \pm \text { SD }\end{array}$ & MD (95\% CI) & P-value & $\begin{array}{c}\text { Male } \\
\text { Mean } \pm \text { SD }\end{array}$ & $\begin{array}{c}\text { Female } \\
\text { Mean } \pm \text { SD }\end{array}$ & MD (95\% CI) & p-value \\
\hline 1 & $23.3 \pm 4.4$ & $23.6 \pm 4.6$ & $-0.4(-1.40 .7)$ & 0.500 & $53.7 \pm 11.7$ & $54.2 \pm 12.8$ & $-0.5(-3.3,2.3)$ & 0.729 \\
7 & $52.4 \pm 2.7$ & $52.4 \pm 3.4$ & $0.0(-0.7,0.7)$ & 0.911 & $29.1 \pm 2.8$ & $30.1 \pm 4.0$ & $-1.0(-1.8,-0.2)$ & 0.013 \\
14 & $79.7 \pm 3.7$ & $78.2 \pm 4.0$ & $1.5(0.6,2.4)$ & 0.001 & $16.6 \pm 0.0$ & $16.9 \pm 1.0$ & $-0.3(-0.5,-0.1)$ & 0.007 \\
21 & $105.1 \pm 3.7$ & $102.9 \pm 3.7$ & $2.1(1.3,3.0)$ & $<0.001$ & $11.0 \pm 0.4$ & $11.4 \pm 0.5$ & $-0.5(-0.6,-0.4)$ & $<0.001$ \\
28 & $127.9 \pm 5.2$ & $123.4 \pm 4.9$ & $4.5(3.3,5.6)$ & $<0.001$ & $8.1 \pm 0.3$ & $8.6 \pm 0.3$ & $-0.5(-0.6,-0.4)$ & $<0.001$ \\
35 & $143.9 \pm 5.2$ & $138.2 \pm 6.2$ & $5.7(4.4,7.0)$ & $<0.001$ & $6.3 \pm 0.2$ & $6.8 \pm 0.3$ & $-0.5(-0.6,-0.5)$ & $<0.001$ \\
\hline
\end{tabular}

CI: confidence interval, MD: mean difference, SD: standard deviation 
Table 6. Regression analysis for estimating the relationship between the absolute bone growth in length and age of broiler chickens

\begin{tabular}{|c|c|c|c|c|c|c|c|}
\hline \multirow{2}{*}{ Variables } & \multirow{2}{*}{ Model equation } & \multirow{2}{*}{ Adjusted $\mathbf{R}^{2}$} & \multicolumn{2}{|c|}{ Constant } & \multicolumn{2}{|c|}{ Age (day) } & \multirow{2}{*}{$\begin{array}{l}\text { p-value } \\
\text { for age }\end{array}$} \\
\hline & & & B & SE & B & SE & \\
\hline \multirow{4}{*}{ Length of backbones (mm) } & Linear & 0.973 & 52.14 & 0.28 & 3.31 & 0.01 & $<0.001$ \\
\hline & Logarithmic & 0.838 & 38.04 & 0.84 & 30.01 & 0.31 & $<0.001$ \\
\hline & Inverse & 0.561 & 129.25 & 0.73 & -84.13 & 1.75 & $<0.001$ \\
\hline & Exponential & 0.924 & 57.51 & 0.27 & 0.03 & 0.00 & $<0.001$ \\
\hline \multirow{4}{*}{ Length of third toe (mm) } & Linear & 0.937 & 23.04 & 0.15 & 1.13 & 0.01 & $<0.001$ \\
\hline & Logarithmic & 0.848 & 17.63 & 0.28 & 10.45 & 0.10 & $<0.001$ \\
\hline & Inverse & 0.589 & 49.51 & 0.24 & -29.84 & 0.59 & $<0.001$ \\
\hline & Exponential & 0.890 & 24.38 & 0.12 & 0.03 & 0.00 & $<0.001$ \\
\hline \multirow{4}{*}{ Length of shank bone (mm) } & Linear & 0.950 & 27.58 & 0.20 & 1.73 & 0.01 & $<0.001$ \\
\hline & Logarithmic & 0.776 & 21.21 & 0.52 & 15.25 & 0.19 & $<0.001$ \\
\hline & Inverse & 0.485 & 67.22 & 0.42 & -41.27 & 1.00 & $<0.001$ \\
\hline & Exponential & 0.933 & 30.77 & 0.13 & 0.03 & 0.00 & $<0.001$ \\
\hline \multirow{4}{*}{ Length of keel bone (mm) } & Linear & 0.974 & 26.40 & 0.28 & 3.46 & 0.01 & $<0.001$ \\
\hline & Logarithmic & 0.868 & 10.37 & 0.79 & 31.92 & 0.29 & $<0.001$ \\
\hline & Inverse & 0.585 & 107.42 & 0.74 & -89.76 & 1.78 & $<0.001$ \\
\hline & Exponential & 0.857 & 31.21 & 0.32 & 0.05 & 0.00 & $<0.001$ \\
\hline
\end{tabular}

B: unstandardized regression coefficient, SE: standard error

Table 7. Regression analysis for estimating the relationship between the relative bone growth in length (expressed as a ratio of bone length to body weight) and age of broiler chickens

\begin{tabular}{|c|c|c|c|c|c|c|c|}
\hline Variables & Model equation & Adjusted $\mathbf{R}^{2}$ & \multicolumn{2}{|c|}{ Constant } & \multicolumn{2}{|c|}{ Age (day) } & $\begin{array}{l}\text { p-value } \\
\text { for age }\end{array}$ \\
\hline \multirow{2}{*}{$\begin{array}{l}\text { Backbones to body weight } \\
(\mathrm{cm} / \mathrm{kg})\end{array}$} & Logarithmic & 0.971 & 111.09 & 0.35 & -31.28 & 0.13 & $<0.001$ \\
\hline & Inverse & 0.939 & 12.13 & 0.26 & 105.37 & 0.63 & $<0.001$ \\
\hline \multirow{3}{*}{$\begin{array}{l}\text { Third toe to body weight } \\
(\mathrm{cm} / \mathrm{kg})\end{array}$} & Linear & 0.661 & 34.89 & 0.41 & -1.15 & 0.02 & $<0.001$ \\
\hline & Logarithmic & 0.952 & 47.14 & 0.19 & -13.44 & 0.07 & $<0.001$ \\
\hline & Inverse & 0.929 & 4.59 & 0.12 & 45.45 & 0.30 & $<0.001$ \\
\hline \multirow{3}{*}{$\begin{array}{l}\text { Shank bone to body weight } \\
(\mathrm{cm} / \mathrm{kg})\end{array}$} & Logarithmic & 0.957 & 62.73 & 0.24 & -17.95 & 0.09 & $<0.001$ \\
\hline & Inverse & 0.962 & 5.67 & 0.12 & 61.63 & 0.29 & $<0.001$ \\
\hline & Exponential & 0.902 & 45.56 & 0.59 & -0.08 & 0.00 & $<0.001$ \\
\hline \multirow{4}{*}{$\begin{array}{l}\text { Keel bone to body weight } \\
(\mathrm{cm} / \mathrm{kg})\end{array}$} & Linear & 0.726 & 43.35 & 0.39 & -1.26 & 0.02 & $<0.001$ \\
\hline & Logarithmic & 0.905 & 54.32 & 0.28 & -13.74 & 0.11 & $<0.001$ \\
\hline & Inverse & 0.792 & 11.34 & 0.22 & 44.02 & 0.53 & $<0.001$ \\
\hline & Exponential & 0.942 & 46.21 & 0.35 & -0.06 & 0.00 & $<0.001$ \\
\hline
\end{tabular}

B: unstandardized regression coefficient, SE: standard error

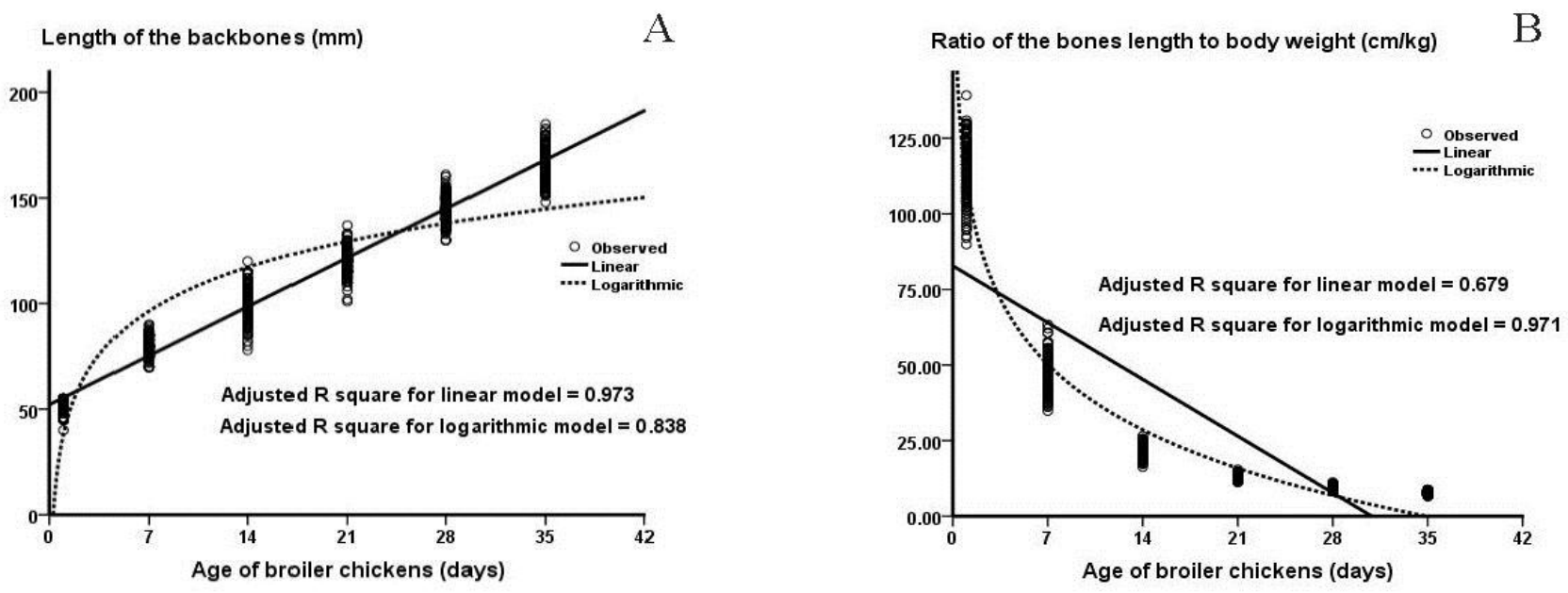

Figure 1. Regression analysis using linear and logarithmic models for the absolute (A) and the relative (B) bone growth in length (expressed as a ratio of bone length to body weight) of the backbones in the broiler chickens during 35 days rearing period. 

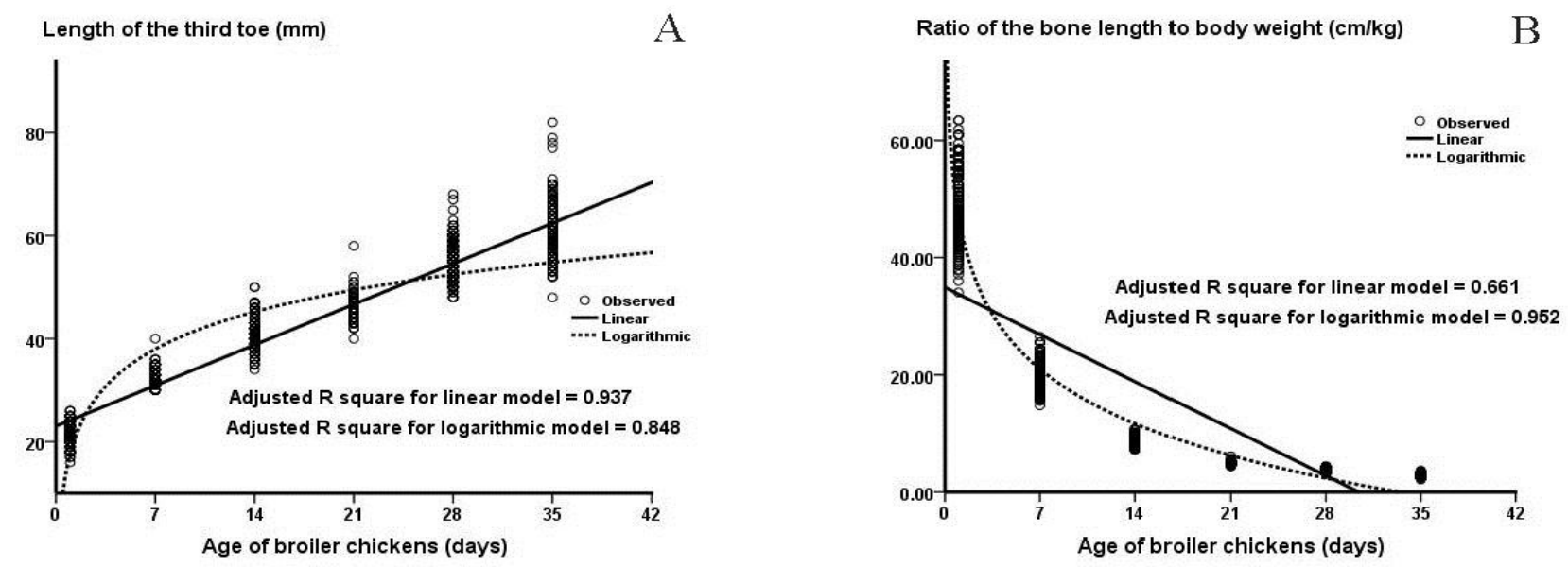

Figure 2. Regression analysis using linear and logarithmic models for the absolute (A) and the relative (B) bone growth in length (expressed as a ratio of bone length to body weight) of the third toe in the broiler chickens during 35 days rearing period.
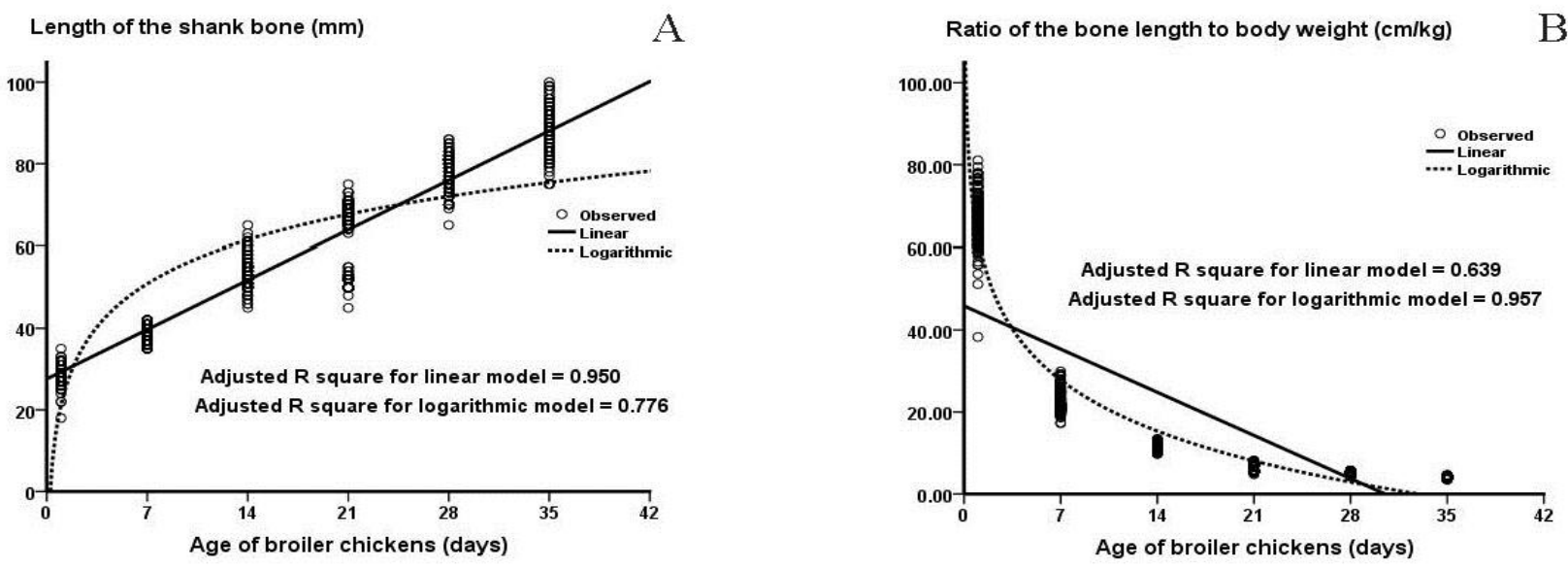

Figure 3. Regression analysis using linear and logarithmic models for the absolute (A) and the relative (B) bone growth in length (expressed as a ratio of bone length to body weight) of the shank bone in the broiler chickens during 35 days rearing period.
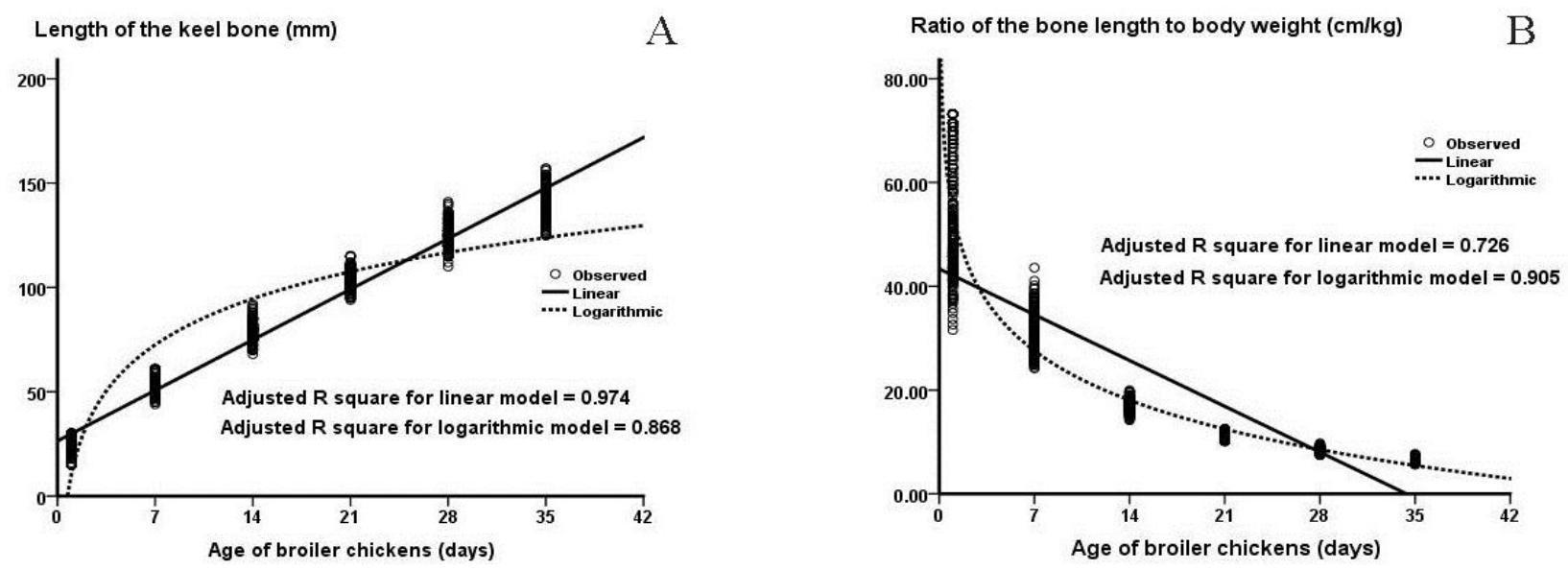

Figure 4. Regression analysis using linear and logarithmic models for the absolute (A) and the relative (B) bone growth in length (expressed as a ratio of bone length to body weight) of the keel bone in the broiler chickens during 35 days rearing period. 


\section{DISCUSSION}

This study indicated that a different mathematical model was acceptable for explaining the absolute and relative bone growth in length as a function of age in commercial broiler chickens. A linear model is more suitable for explaining the absolute bone growth in length in commercial broilers because an adjusted $\mathrm{R}^{2}$ value (indicating model fitting) of the linear model was higher than that of the other models. The adjusted $\mathrm{R}^{2}$ values for the linear model of the absolute bone growth in length ranged from 0.937 for the third toe and to 0.974 for the keel bone, which were higher than those of the other models for all of the studied bones (Table 6). This result means that the age of the chickens can explain approximately $93.7 \%$ and $97.4 \%$ of the variability in bone growth in length for the third toe and the keel bone, respectively. However, it appeared that a logarithmic model is more suitable for explaining the relative bone growth in length in commercial broiler chickens. Adjusted $\mathrm{R}^{2}$ values for assessing a logarithmic model fitting of the relative bone growth in length ranged from 0.905 for the keel bone to 0.971 for the backbones, which was higher than those of the other models for most of the studied bones (Table 7). This finding indicates that the age of the chickens can explain approximately $90.5 \%$ and $97.1 \%$ of the variability in bone growth in length for the keel bone and the backbones, respectively.

In the linear model, the absolute bone growth in length linearly increased with age for all of the studied bones. The rate for the absolute bone growth in length was the highest for the keel bone (the regression coefficient = 3.46) and was the lowest for the third toe (the regression coefficient $=1.13)($ Table 6$)$. This outcome meant that the keel bone growth in length increased from $29.9 \mathrm{~mm}$ at 1 day to $147.5 \mathrm{~mm}$ at 35 days of age, but the third toe growth in length increased from $24.2 \mathrm{~mm}$ at 1 day to 62.6 $\mathrm{mm}$ at 35 days of age. Several studies have evaluated longitudinal bone growth in broiler chickens (Applegate and Lilburn, 2002; Biesiada-Drzaga et al., 2012; Shim et al., 2012; Han et al., 2015; Mabelebele et al., 2017). The results of previous studies were similar to the obtained results in the current study. That is, the absolute bone growth in length in the broiler chickens was positively increased with age (Biesiada-Drzaga et al., 2012; Han et al., 2015) or with body weight (Applegate and Lilburn, 2002; Paxton et al., 2014; Mabelebele et al., 2017). The present study also indicated that the rate of longitudinal bone growth differed depending on the studied bones. This difference may result in bone length reaching a plateau or maturity at different ages. The statement was also supported by evidence from a previous study, conducted in broiler chickens from hatch to 43 days of age, which reported the length of the femur reached a plateau at 35 days of age, but the length of the tibia reached a plateau later than 43 days of age (Applegate and Lilburn, 2002). In addition, this finding was similar to longitudinal bone growth in other poultry species, such as ducks (Van Wyhe et al., 2012).

In a logarithmic model, the relative bone growth in length logarithmically decreased with age. It was indicated that the relative bone growth in length decreased sharply from 1 day to 14 days of age but slightly decreased from 21 days through 35 days (Figure 1B-4B). The rate of the relative bone length was negative, with the lowest rate for the backbones (regression coefficient $=-31.28$ ) and the highest rate for the third toe (regression coefficient = 13.44). Moreover, it was determined that the relative length of the backbones decreased from $109.60 \mathrm{~cm} / \mathrm{kg}$ (or $1.10 \mathrm{~mm} / \mathrm{g}$ ) at 1 day to $69.23 \mathrm{~cm} / \mathrm{kg}$ (or $0.69 \mathrm{~mm} / \mathrm{g}$ ) at 28 days of age, but the third toe growth in length decreased from $46.02 \mathrm{~cm} / \mathrm{kg}$ (or $0.46 \mathrm{~mm} / \mathrm{g}$ ) at 1 day to $15.56 \mathrm{~cm} / \mathrm{kg}$ (or $0.16 \mathrm{~mm} / \mathrm{g}$ ) at 28 days of age. The obtained results in current work were similar to those of a previous study by Shim et al. (2012), who found the relative bone growth in length decreased with body weight in both fast-growing and slow-growing broiler chickens.

The results obtained in the present article varied in overall comparisons of bone growth in length between male and female broiler chickens for all ages. However, at 28 days and 35 days of age, the absolute bone growth in length was significantly higher in males than in females for all of the studied bones. On the other hand, the relative bone growth in length was significantly lower in males than in females from 7 days through 35 days of age (Tables 2-5). The different results between the absolute and relative bone growth in length implied the importance of different rates of body weight gain between males and females (Table 1). The results from previous studies were also controversial. In one study, there was no significant difference in absolute bone length between male and female broiler chickens (Han et al., 2015). In other studies, male broiler chickens had longer tibias and femurs than female broiler chickens (Bond et al., 1991; Applegate and Lilburn, 2002).

The present study has some limitations. There are several factors that regulate bone growth and strength in poultry (Rath et al., 2000). However, the current investigation focused only on bone growth in length and ignored circumferential growth, weight, and volume of 
bones as well as the degree of mineralization which were studied in previous literature (Kerschnitzki et al., 2016; Pratt and Cooper, 2018; Sanchez-Rodriguez et al., 2019). These factors affect the bone strength for supporting the whole body weight. In addition, the age of broiler breeder flocks was not available in the current study. Different ages of broiler breeder may result in differences in bone length and body weight of broiler chickens. Therefore, the aforementioned limitations should be taken into account in the interpretation of bone growth in this study, which should be made carefully.

\section{CONCLUSION}

The present study demonstrated that a simple linear model is a suitable model to explain the increase in the absolute bone growth in length as a function of age; however, a logarithmic model is an acceptable model to explain the decrease in the relative longitudinal bone growth as a function of age in commercial broiler chickens.

\section{DECLARATIONS}

\section{Acknowledgments}

This study was supported by the Research Group on Toxic Substances in Livestock and Aquatic Animals and the Faculty of Veterinary Medicine, Khon Kaen University.

\section{Consent to publish \\ Not applicable}

\section{Competing interests} exists.

The authors have declared that no competing interest

\section{Author's contribution}

Saijai, Damnern, and Peerapol participated in study design, data collection, data analysis, writing, and approving the final manuscript.

\section{REFERENCES}

Applegate TJ and Lilburn MS (2002). Growth of the femur and tibia of a commercial broiler line. Poultry Science, 81(9): 1289-1294. DOI: https://doi.org/10.1093/ps/81.9.1289.

Biesiada-Drzaga B, Bombik T, Rojek A, Kubiak M, Penda M, and Brodzik U (2012). Growth of selected bones and muscle groups in broiler chickens during rearing period. Acta Scientiarum Polonorum Zootechnica, 11(1): 25-34. Available at: https://asp.zut.edu.pl/downld/asp-2012-11-1137.pdf.

Bond PL, Sullivan TW, Douglas JH and Robeson LG (1991). Influence of age, sex, and method of rearing on tibia length and mineral deposition in broilers. Poultry Science, 70(9): 1936-1942. DOI: https://doi.org/10.3382/ps.0701936.

Cook ME (2000). Skeletal deformities and their causes: Introduction. Poultry Science, 79(7): 982-984. DOI: https://doi.org/10.1093/ps/79.7.982.

Granquist EG, Vasdal G, de Jong IC and Moe RO (2019). Lameness and its relationship with health and production measures in broiler chickens. Animal, 21: 1-8. DOI: https://doi.org/10.1017/S1751731119000466.

Han J, Qu H, Wang J, Chen G, Yan Y, Zhang J, Hu F, You L and Cheng Y (2015). Comparison of the growth and mineralization of the femur, tibia, and metatarsus of broiler chicks. Brazilian Journal of Poultry Science, 17(3): 333340. DOI: http://dx.doi.org/10.1590/1516-635X1703333340.

Kerschnitzki M, Akiva A, Ben Shoham A, Asscher Y, Wagermaier W, Fratzl P, Addadi L and Weiner S (2016). Bone mineralization pathways during the rapid growth of embryonic chicken long bones. Journal of Structural Biology, 195(1): $\quad 82-92 . \quad$ DOI: https://doi.org/10.1016/j.jsb.2016.04.011.

Knowles TG, Kestin SC, Haslam SM, Brown SN, Green LE, Butterworth A, Pope SJ, Pfeiffer D and Nicol CJ (2008). Leg disorders in broiler chickens: Prevalence, risk factors and prevention. PLOS ONE, 3(2): e1545. DOI: https://doi.org/10.1371/journal.pone.0001545.

Kokoszyński D and Bernacki Z (2008). Comparison of slaughter yield and carcass tissue composition in broiler chickens of various origin. Journal of Central European Agriculture, 9(1): 11-16. Available at: https://jcea.agr.hr/articles/500_comparison_of_slaughter_yi eld_and_carcass_tissue_composition_in_broiler_chickens_o f_various_origin_en.pdf.

Mabelebele M, Norris D, Siwendu N, Ng'ambi J, John A and Mbajiorgu CA (2017). Bone morphometric parameters of the tibia and femur of indigenous and broiler chickens reared intensively. Applied Ecology and Environmental Research, 15(4): 1387-1398. DOI: http://dx.doi.org/10.15666/aeer/1504_13871398.

Paxton H, Tickle PG, Rankin JW, Codd JR and Hutchinson JR (2014). Anatomical and biomechanical traits of broiler chickens across ontogeny. Part ii. Body segment inertial properties and muscle architecture of the pelvic limb. PeerJ, 3(2): e473. DOI: https://doi.org/10.7717/peerj.473.

Pratt IV and Cooper DML (2018). The effect of growth rate on the three-dimensional orientation of vascular canals in the cortical bone of broiler chickens. Journal of Anatomy, 233(4): 531-541. DOI: https://doi.org/10.1111/joa.12847.

Rath NC, Huff GR, Huff WE and Balog JM (2000). Factors regulating bone maturity and strength in poultry. Poultry Science, 79(7): 1024-1032. DOI: https://doi.org/10.1093/ps/79.7.1024.

Rose N, Constantin P and Leterrier C (1996). Sex differences in bone growth of broiler chickens. Growth, Development and Aging, 60(2): 49-59.

Sanchez-Rodriguez E, Benavides-Reyes C, Torres C, Dominguez-Gasca N, Garcia-Ruiz AI, Gonzalez-Lopez S and Rodriguez-Navarro AB (2019). Changes with age (from 0 to $37 \mathrm{~d}$ ) in tibiae bone mineralization, chemical 
composition and structural organization in broiler chickens. Poultry Science, pez363. DOI: https://doi.org/10.3382/ps/pez363.

Sarsenbek A, Wang T, Zhao JK and Jiang W (2013). Comparison of carcass yields and meat quality between Baicheng-You chickens and Arbor Acres broilers. Poultry Science, 92(10): 2776-2782. DOI: https://doi.org/10.3382/ps.2012-02841.

Shim MY, Karnuah AB, Mitchell AD, Anthony NB, Pesti GM and Aggrey SE (2012). The effects of growth rate on leg morphology and tibia breaking strength, mineral density, mineral content, and bone ash in broilers. Poultry Science, 91(8): 1790-1795. DOI: https://doi.org/10.3382/ps.201101968.

Tallentire CW, Leinonen I and Kyriazakis I (2018). Artificial selection for improved energy efficiency isreaching its limits in broiler chickens. Scientific Reports. 8(1): 1168. DOI: https://doi.org/10.1038/s41598-018-19231-2.

Van Wyhe RC, Applegate TJ, Lilburn MS and Karcher DM (2012). A comparison of long bone development in historical and contemporary ducks. Poultry Science, 91(11): 2858-2865. DOI: https://doi.org/10.3382/ps.2012-02385. 